THERAPISTS' EXPERIENCES OF RELATIONAL DEPTH: A QUALITATIVE INTERVIEW STUDY

MICK COOPER

COUNSELLING UNIT, UNIVERSITY OF STRATHCLYDE, GLASGOW (MICK.COOPER@STRATH.AC.UK)

PUBLISHED IN:

COUNSELLING AND PSYCHOTHERAPY RESEARCH, 5(2), 87-95. 2005. 


\section{THERAPISTS' EXPERIENCES OF RELATIONAL DEPTH: A QUALITATIVE INTERVIEW STUDY}

Abstract: The aim of this study was to explore therapists' experiences of meeting their clients at a level of 'relational depth'. This was defined as a feeling of profound contact and engagement with another, in which the therapists experienced high levels of empathy, acceptance and transparency towards their clients, and experienced their clients as acknowledging their empathy and acceptance in a genuine way. Participants were primarily experienced person-centred therapists, five of whom were female and three of whom were male. Data was gathered through the use of qualitative, unstructured interviews within the broader framework of a person-centred and phenomenological research approach. All interviewees described experiencing moments of relational depth with their clients, and substantial commonalities emerged in their descriptions. These included heightened feelings of empathy, acceptance and receptivity towards their clients; powerful feelings of immersion in the therapeutic work; increased perceptual clarity; and greater levels of awareness, aliveness and satisfaction. At these times, the therapists also experienced their clients as highly transparent; articulating core concerns and issues; and reciprocating the therapist's acknowledgement of them in a flowing, bi-directional encounter. These findings are discussed in relation to recent research on 'presence' and 'flow', and it is proposed that relational depth can be conceptualised as a form of 'co-presence' or a co-experiencing of the person-centred 'core conditions'. Limitations of the study and areas for further research are discussed. 
Experiencing relational depth

Key words: relational depth, presence, person-centred therapy, therapeutic relationship, qualitative research, therapists' experiences 
From the earliest days of counselling and psychotherapeutic research (e.g. Rogers, 1957) to the most recent 'mega-analytical' investigations (e.g. Norcross, 2002), empirical researchers have devoted considerable time and attention to an examination of the therapeutic relationship and its correspondence to the successfulness of therapy. Today, a substantial body of evidence suggests that the quality of the therapeutic relationship is one of the key factors in determining outcomes (see summaries in Cooper, 2004; Norcross, 2002), and many leading psychotherapy researchers consider it second only to the client's own resources and extra-therapeutic experiences in predicting how successful therapy will be (Hubble, Duncan, \& Miller, 1999; Lambert \& Barley, 2002).

In recent years, much of this work has focused on the 'therapeutic alliance': 'the quality and strength of the collaborative relationship between client and therapist in therapy' (Hovarth \& Bedi, 2002, p.41). There has also been a focus on such relational variables as the establishment of shared goals between therapist and client (Tryon \& Winograd, 2002). One area that has yet to be examined in any empirical depth, however, is the more profound feelings of connectedness and relating that, for many therapists, are at the heart of their therapeutic practice (for instance, Friedman, 1985; Mearns \& Cooper, in print; Stern, 2004).

Such experiences of in-depth connectedness have been conceptualised in many ways across many therapeutic orientations. From the psychodynamic field, for instance, Stern $(2004 ; 1998)$ has described 'moments of meeting,' in which a 'mutual interpenetration of minds' takes place; whilst Ehrenberg writes of the 'intimate edge': 'the point of maximum and acknowledged contact at any given moment in a 
relationship without fusion' (1992, p.33, italics as per original). From the related field of feminist therapy, Jordan writes of 'mutual intersubjectivity,' in which, 'one is both affecting the other and being affected by the other; one extends oneself out to the other and is also receptive to the impact of the other' (1991, p.82). Existential and humanistic therapist, such as Friedman (1985) and Hycner (1991), have also described moments of 'I-Thou' meeting and 'dialogue' in the therapeutic encounter, drawing upon the work of the existential philosopher, Martin Buber (1958).

In the field of person-centred therapy, Mearns (1997; 2003; Mearns \& Cooper, in print) has also written about an 'extraordinary depth of human contact' (2003, p.5), and has termed this 'relational depth.' For Mearns, such relational depth consists of a 'blending together of high degrees of the three core conditions of empathy, unconditional positive regard and congruence' (2003, p.8), alongside the other Rogerian (1957) 'conditions' of 'contact' and 'perception' (i.e. the client perceives the counsellor's empathic understanding and unconditional positive regard to a minimal degree). Mearns likens such relational depth to Rogers' (1986) notion of 'presence': moments in which the therapist's 'inner spirit' seems to reach out and touch the inner spirit of the other, and she or he is closest to his or her 'inner, intuitive self.'

The experience of presence have been investigated empirically by Geller (Geller \& Greenberg, 2002). Geller conducted in depth interviews with seven experienced therapists from a range of orientations, in which they were asked to reflect on, and report, their own experiences of presence with clients. At these times, Geller's participants described being fully receptive to their clients in a bodily, emotional and mental way; attending to their own spontaneous, intuitive responses to the client; and 
extending themselves to the client in a very immediate and congruent way. Therapists also described an immersion and absorption in the present; a sense of expansion, timelessness and an enhanced awareness of sensations and perceptions; a feeling of being grounded and centred; and feelings of warmth, compassion and 'being there' for the client.

It is important to note, however, that the concept of presence, as defined and examined by Geller and Greenberg (2002) (and to some extent described by Rogers (1980)), is construed primarily in terms of the therapist's experiencing - both within themselves and towards their clients - rather than in terms of the relationship between therapist and client. Conceptually, then, it would seem somewhat distinct - though closely related - to the notions of an in depth therapeutic connection, which exist between therapist and client, rather than within the former.

The aim of the present study, then, was to see whether therapists do experience some sense of deep connectedness with their clients in therapy; and to develop a greater understanding of what these experiences are like.

\section{Methodology}

\section{Participants}

Once ethical approval had been received from the University of Strathclyde, pilot interviews were carried out with four colleagues of the researcher, all of whom were experienced person-centred therapists and trainers with an average of fourteen years in practice. These interviews produced richly descriptive data, and no major difficulties with the research procedure were identified by either researcher or 
participants. For these reasons, it was decided to treat the data from these interviews as part of the main body of data. Four further interviews were then conducted with practicing therapists who had volunteered to take part in a study of relational depth, and felt that they had some experience of such meetings with clients. Three of these considered themselves primarily person-centred and one primarily solution-focused. On average, they had four years experience of practicing therapy. In total, five females and three males were interviewed for the study.

\section{Procedure}

Having volunteered to take part in the study, all participants were sent an information sheet which gave them detailed information about the aims of the study and the interviewing process. Participants were informed that they would be asked about their experiences of meeting client(s) at a level of relational depth, and that they would not be required to disclose any identifying or specific details about their clients. To prepare for the interviews, participants were asked to think about specific times, particularly recent ones, in which they felt that they had engaged with their client at a high level of relational depth. For the purposes of this study (and in consultation with Professor Mearns), relational depth was defined to the participants as:

[A] feeling of profound contact and engagement with an Other, in which one simultaneously experiences extremely high and consistent levels of empathy and acceptance towards that Other, and relates to them in a highly transparent way. In this relationship, the Other is experienced as acknowledging one's empathy and acceptance - either implicitly or explicitly - and is experienced as fully congruent and real. 
Each of the interviews lasted approximately forty minutes, and took the form of a qualitative, nonstandardised, unstructured inquiry (Kvale, 1996), within the broader framework of a person-centred (Mearns \& McLeod, 1984) and phenomenological (e.g. Moustakas, 1994) research approach. Hence, an interview guide was used to ensure that basic questions were addressed, but the primary aim of the interview was to engage the participants in an in-depth, interactive dialogue, in which spontaneous, creative and richly descriptive responses would have the optimal possibility of emerging.

\section{Analysis}

Interviews were transcribed and then sent to the participants for checking. They were then analysed with the aid of NVivo, a qualitative analysis software package. In order to undertake this analysis, the researcher first read through each of the interviews and identified some common themes. These were then entered into the NVivo program as categories and sub-categories (or, in NVivo language, 'nodes'), and each of the interviews were coded according to these categories, with substantial revision, refinement, deletion, and addition of categories throughout this process. The researcher then went through each of the categories, checking the correspondence between category and data: a process which, again, entailed substantial rearrangement of categories and re-coding of material. Category by category, the responses were then written up in the form of a narrative: a process which, again, involved some recoding of material and rearrangement of categories. Each of the interviews were then read through again with their 'coding stripes' in view, such that the validity of the coding could be re-checked. Following some further minor revisions to the coding and narrative, a first draft of the whole paper was sent out to the participants, to check that 
the write-up accurately incorporated their views. This led to a final version of the narrative.

To present some idea of the frequency of responses and their representativeness, the conventions adopted by Hill (1997) (and originally formulated by Elliott) were used in the write-up of the research. Here, categories that applied to all cases were considered general; those that applied to between all and half were considered typical; those that applied to between half and two were considered variant (the term 'some' was also used here), and those that applied to only one respondent were generally dropped from the narrative. Exact frequencies for the main categories and subcategories are given in table one.

\section{The researcher}

I am a UKCP-registered psychotherapist whose practice combines elements of person-centred and existential practice, and draws strongly from the work of Buber (1958) and other intersubjective philosophers and therapists (e.g. Spinelli, 1997). For me, meeting clients at a level of relational depth is a central aim of my therapeutic work and I would claim to have had many experiences of meeting clients at this level, though I often struggle to attain such depths of connection. Such experiences, for me, are characterised by a sense of ease, enjoyment and concentration: an entering into the world of an Other, and a sense of being welcomed and valued there. 


\section{Results}

\section{Experiences of relational depth}

All participants could identify one or more times when they felt they had encountered their clients at a level of relational depth, as defined in this study. Below is an example of one such moment of meeting:

During the session what he was telling me was how much I mattered to himnot just the counselling mattered to him, but me.... There was a real vitality in that and I knew the vitality of it. I could tell in the way he was saying it.... [T]here was something of a knowing who we were to each other in that moment that was really, really important, and, um, there was something about I - what I felt was complete trust of myself and him as well as in that moment.

In terms of the qualities of this experience, table one presents a summary of the main categories and sub-categories (indented) emerging from the qualitative analysis, and their frequencies. They have been divided into: therapists' experiences of themselves at these moments of meetings, their experiences and perceptions of their clients, and their experiences of the therapist-client relationship.

[Insert table one about here]

\section{Self-experiences}

As suggested in the definition of relational depth given to the participants, counsellors typically described experiencing high levels of empathy at these times. One 
participant, for instance, likened it to walking into the same room as the client and really knowing that both of you are in the same place, even though you had both walked in through different doors. At these times of relational depth, some of the participants emphasised that this was an empathy to all of the client: for instance, their past and their present; their different 'configurations of self' (Mearns \& Thorne, 2000); or their conflicting voices, and including that part of them that may be terrified of relating in an in depth way. For some of the participants, this experiencing of empathy could be highly somatic (cf. 'embodied empathy,' Cooper, 2001): an internal mirroring of what the client was sensed to be experiencing inside their bodies.

With respect to empathic attunement, participants typically said that, at these times of relational depth, they experienced their clients and their world with a greater perceptual clarity. One participant likened this to being very short-sighted and putting on glasses, such that what is going on suddenly becomes 'sharp,' 'distinct' and in focus.

In general, participants also reported experiencing high levels of congruence at these times: 'there's something about being absolutely there just as a person.' Some of the participants described how, at those times, they acted in more spontaneous, flowing ways: more willing to take risks. Some of the participants also talked about bringing more of themselves in to the relationship at these times, such as the vulnerable parts of themselves.

Closely related to this, a typical response given by participants was that, at these times of relational depth, they felt 'impacted' upon by their clients: 'affected,' 'touched,' 
'moved' or 'influenced.' One participant said: 'maybe, in a way, you can say that I learnt something from them too.... [M]aybe it's a moment of change.... in me as well. I'm a bit different.' Some of the participants also described how they felt a sense of openness to the client at these times.

A 'deep acceptance of the client' was also a typical feature of these experiences of relational depth. One participant said, 'it's almost as if your heart opens'; another described it as a feeling of being 'privileged to be there'; and another likened it to the experience of love.

Another typical aspect of the relationally-deep encounter was a sense of being 'immersed' in - or 'involved' 'focused' or 'engaged' with - the client and the therapeutic work. For instance, one participant said, "in the moment of connection...nothing else in my life matters to me beyond that.' As part of this, participants typically reported a sense of being free from distractions, both internal (e.g. wandering thoughts) and external (e.g. noises) at these times. One participant described this as her and her client being immersed in a powerful, protective 'sphere'; and another participant, very similarly, talked about feeling that she and her client were in a 'bubble', in which what was going on around them was 'irrelevant and quite hazy,' whilst what was going on between them was 'really sharply in focus.' Here, some of the participants specifically talked about being immersed in the moment and, for one participant, this was to such an extent that she often found it difficult to remember what had actually taken place at these times. Indeed, it was typical for participants to described features of a relationally-deep encounter that would more commonly be associated with altered states of consciousness, such as feeling 
physically lighter; being in a 'stupor'; or changes in perceptions of time, such that fifty minutes could pass in a flash, or a few minutes could seem to last for hours.

Typically, participants described feeling very alive, energised, excited and stimulated at those moments of relational depth: like suddenly being 'wide awake.' Some of the participants, however, added that after such meetings they sometimes felt drained and exhausted. Along these lines, some of the participants talked about the way that there was always some emotional charge to their experiences of relational depth, 'as opposed to a lack of emotion or a flatness.'

The experience of meeting clients at a level of relational depth was also typically accompanied by feelings of satisfaction, a sense that 'This is what counselling is all about.' One participant said, 'There's something that's far more, kind of, satisfying about that than, kind of working at a..."doggy paddle” kind of depth.' Participants typically added that there was a sense of 'rightness' when meeting clients at the level: 'it kind of feels like that's where you want to be.' Some of the participants also talked about an active sense of happiness or enjoyment at those times; whilst some described a sense of optimism or hope for the clients at those times of meeting. Some also described feeling 'safer' when working with clients at this level: less scared or frightened of the client's material.

\section{Perceptions of the client}

As suggested in the definition of relational depth given to participants, interviewees typically talked about perceiving their clients as very transparent and real at those moments of relational depth: a 'complete presence in the moment.' One participant, 
for instance, described a client who often presented herself as bubbly, bright and chirpy but who, in those moments of relational depth, would reveal her real pain, sadness and loneliness. Along these lines, all of these participants said that, at these moments of relational depth, clients were expressing something - or communicating from a place - that was at the very core of their being: something 'substantial', 'nonsuperficial', 'deeply meaningful', 'important,' 'significant,' 'profound,' 'deeply personal,' 'a very, very private place.' One participant described it in the following way:

[I]magine being in a house in which...in every room there is something...very scary, or dangerous animals... and you say, 'Oh yes, it was quite dangerousthis is quite dangerous...' and then you go in this room and this is the real one, you know. You're thinking about this dangerous with all the animals, but the real one- the rest is like 'baby stuff.'

In relation to this, participants typically said that, at those moments of relational depth, the client seemed particularly in touch with - or to come from - a place of vulnerability, and some of the participants described the way in which, at moments of relational depth, clients seemed more connected with their stories at an emotional level. Some of the participants also said that, at these moments of relational depth, clients seemed in touch with something new, something at the edges of their awareness.

\section{Experiencing the relationship}

At these times of relational depth, participants typically described feelings of closeness or intimacy with their clients. Some of the participants described a feeling 
of 'flow' (cf. Csikszentmihalyi, 2002): an 'ease in the relationship', and one participant likened this to having a 'tube' between their world and the world of the client, where, 'they can... somehow exchange the blood and the cells and whatever': the essences of their worlds.

As suggested in the given definition of relational depth, in general, participants said that such moments did not just consist of them providing a set of conditions for the client, but, in some way, the client reciprocating that way of meeting. Here, then, was a 'mutuality,' a 'symmetry,' a 'two-way' relationship, a feeling 'that we are doing this together.' Typically, for instance, participants described a 'co-openness' or 'cotransparency' that occurred at those moments, one participant likening it to clear water in a pond, where both therapist and client can see, and be seen, right down to their very depths. Along similar lines, some of the participants said that, at those moments of relational depth, neither they nor their clients were wearing 'masks,' 'pretences' or 'layers of false bits': just two very naked people, a 'touching of souls.' Similarly, participants typically described a 'co-acceptance' at those moments of relational depth: a mutual respect in which 'the client perceives me as a human being and... similarly there is a return of that.'

Typically, however, participants went beyond this, suggesting that, at those moments of relational depth, it was not just that they and the client experienced similar attitudes towards each other, but that the client experienced those attitudes towards the therapist's experiencing of those attitudes towards them. In other words, it was not just that therapist and client acknowledged each other, but that the client acknowledged the therapist's acknowledgement of them. One participant, for instance, 
used the metaphor of the client having their 'eyes wide open': such that 'they can perceive me and know that I am responding to them.'

Along these lines, some of the participants talked about the way that, at moments of relational depth, the client seems to know that the therapist 'knows' them: 'They know I understand what's going on for them at a really deep level... the client is open to what I have to offer, the client is receiving my empathy.' Another participant said: 'They absolutely know that you are with them.' Similarly, some of these participants described how, at these moments of relational depth, they experienced the client as accepting their acceptance of them (cf. Tillich, 2000): 'It feels as though they knowthey get a sense that they matter to me.' Another participant said: 'relational depth, for me, is only when the client has really accepted me into their world. That's when...the going deeper takes place.' Conversely, however, one of the therapists described how relational depth had only come about once she, as the therapist, had overcome her shyness and allowed herself to take in the client's accepting and valuing of her.

In terms of relational processes, participants typically stated that relational depth may be manifested in a non-verbal way - particularly through eye-contact - as well as verbally. One participant said, 'for me, it's not often characterised by a lot of talking. I mean, the client may speak but I may not say... a huge amount.'

\section{Discussion}

From these results, it would seem that there is a high degree of overlap in how therapists, primarily of a person-centred orientation, experience moments of relational 
depth with their clients. Participants confirmed that, at these times, they experienced high levels of congruence, acceptance and empathy towards their clients, and that they experienced their clients as congruent and real, and acknowledging of their acknowledgement. More than that - and entirely independently - many participants also talked about feeling immersed, awake and impacted upon at these times; more able to see things clearly, and highly satisfied with their work. This suggests that the experience of in depth connection with clients - whether termed 'relational depth', 'moments of meeting,' etc. - is a real and distinctive occurrence within the therapeutic encounter and worthy of further empirical examination.

Such a conclusion is supported by the fact that the experiences described by participants in this study are remarkably similar to those described by participants in Geller and Greenberg's (2002) research. There, too, therapists described moments of immersion and absorption in the present, a sense of timelessness, an enhanced awareness of sensations and perceptions, a sense of being highly receptive - often in a physical way - towards their clients and a strong feeling of 'being with' them. What is also striking is the correspondence between these descriptions of relational depth/presence and Csikszentmihalyi's (2002) account of the experience of 'flow'- a total, un-self-conscious involvement in an activity - that thousands of people have described in all walks of life. Here, too, individuals talk about feelings of immersion, heightened perceptual awareness, satisfaction and changes in their perception of time.

In this study, however, participants' described a phenomenon that went somewhere beyond the experiencing of 'presence' or 'flow'; for not only did therapists experience a presence towards their clients, but also a presence from their clients back towards 
them. Perhaps, then, in R. D. Laing's terms (van Deurzen, 2004, personal communication), one might term this a 'co-presence'; or a 'co-flow'; or perhaps, even, a moment in which both therapist and client are experiencing the 'core conditions' towards each other. More than that, what is being proposed here - and to some extent identified -are moments in which the client's presence to the therapist's presence, or the therapist's flow in response to the client's flow, creates a synergistic encounter that may not be reducible to the sum of its individual parts.

As a preliminary investigation into the phenomenon of in depth therapeutic connectedness, this study opens up many more questions than it answers. Aside from further qualitative research to broaden and deepen an understanding of how this phenomenon is experienced, it would also be very useful to see whether therapist of less relationship-orientated approaches - such as cognitive-behavioural therapies also experience such moments of meetings (I strongly suspect they do). In subsequent studies, it would also be useful to work with participants who have less of a professional connection with the researcher, such that they are less likely to be influenced by demand characteristics of the situation (participants in the present study, for instance, may have been reluctant to tell a fellow person-centred trainer that they had never experienced moments of relational depth with their clients). In developing this line of research, other important steps forward would be to see whether clients experience such moments of meeting as well (I expect they do, but describe it in very different ways), and whether clients experience them at the same time as therapists do (I suspect there are more asynchronies here than many therapists would assume). Most importantly, though, is the question of whether the experiencing of relational depth is related to therapeutic outcome. On the basis of Mearns' (Mearns 
\& Cooper, in print), Stern's (2004) and related writers' theorising, the hypothesis would be that the experiencing of relational depth is one of the best predictors of therapeutic outcomes and, if this were found to be the case, this would have major implications for the practice, training and researching of therapy. Perhaps the most important contribution of the present study, then, is to help pave the way towards an operationalisation of the concept of relational depth (through, for instance, the development of an in-session measure), such that the link between experiences of therapist-client connectedness and therapeutic outcomes can be evaluated.

\section{Conclusion}

This study has found that therapists, primarily of a person-centred orientation, do experience moments of relational depth with their clients, and that there are strong similarities in their descriptions of this experience. Not only is it characterised by high levels of empathy, acceptance and genuineness towards clients; but also by feelings of aliveness, receptivity, satisfaction and immersion. At these times, therapists also experience their clients as very real, in touch with core aspects of themselves, and acknowledging the therapist's acknowledgement in a reciprocal, bi-directional encounter. Such experiences would seem to have many similarities to the experience of presence or flow, but may be more accurately characterised as 'co-presence' or 'coflow' and would seem to be worthy of further empirical investigation - particularly with a view to assessing their relationship to therapeutic outcomes. 


\section{References}

Buber, M. (1958) I and Thou (R. G. Smith, Trans. 2nd ed.). Edinburgh: T \& T Clark Ltd.

Cooper, M. (2001). Embodied empathy. In S. Haugh \& T. Merry (Eds.), Empathy (pp. 218-229). Ross-on-Wye: PCCS Books.

Cooper, M. (2004) Towards a relationally-orientated approach to therapy: Empirical support and analysis. British Journal of Guidance and Counselling, 32(4).

Csikszentmihalyi, M. (2002) Flow: The classic work on how to achieve happiness. London: Rider.

Ehrenberg, DB. (1992) The Intimate Edge: Extending the Reach of Psychoanalytic Interaction. New York: W. W. Norton.

Friedman, M. (1985) The Healing Dialogue in Psychotherapy. New York: Jason Aronson, Inc.

Geller, SM, \& Greenberg, LS. (2002) Therapeutic presence: Therapist's experience of presence in the psychotherapy encounter. Person-Centered and Experiential Psychotherapies, 1(1\&2) 71-86.

Hill, CE, Thompson, BJ, \& Williams, EN. (1997) A guide to conducting consensual qualitative research. The Counselling Psychologist, 25(4) 517-572.

Hovarth, AO, \& Bedi, RP. (2002). The alliance. In J. C. Norcross (Ed.), Psychotherapy Relationships that Work: Therapist Contributions and Responsiveness to Patients (pp. 37-69). Oxford: Oxford University Press.

Hubble, M, Duncan, BL, \& Miller, SD. (1999) The Heart and Soul of Change: What Works in Therapy. Washington, DC: American Psychological Association. Hycner, R. (1991) Between Person and Person: Towards a Dialogical Psychotherapy. Highland, NY: Gestalt Journal Press. 
Jordan, JV. (1991). The development of women's sense of self. In J. V. Jordan, A. G. Kaplan, J. B. Miller, I. P. Stiver \& J. L. Surrey (Eds.), Women's Growth in Connection: Writings from the Stone Centre (pp. 81-96). New York: The Guilford Press.

Kvale, S. (1996) InterViews. London: Sage.

Lambert, MJ, \& Barley, DE. (2002). Research summary on the therapeutic relationship and psychotherapy outcome. In J. C. Norcross (Ed.), Psychotherapy Relationships that Work: Therapist Contributions and Responsiveness to Patients (pp. 17-32). Oxford: Oxford University Press.

Mearns, D. (1997) Person-Centred Counselling Training. London: Sage.

Mearns, D. (2003) Developing Person-Centred Counselling (2nd ed.). London: Sage. Mearns, D, \& Cooper, M. (in print) Working at Relational Depth in Counselling and Psychotherapy. London: Sage.

Mearns, D, \& McLeod, J. (1984). A person-centred approach to research. In R. F. Levant \& J. M. Shlein (Eds.), Client Centred Therapy and the Person-Centred Approach: New Directions in Theory, Research and Practice (pp. 370-389). Eastbourne: Praeger.

Mearns, D, \& Thorne, B. (2000) Person-Centred Therapy Today: New Frontiers in Theory and Practice. London: Sage.

Moustakas, C. (1994) Phenomenological Research Methods. London: Sage.

Norcross, JC (Ed.). (2002) Psychotherapy Relationships that Work: Therapists Contributions and Responsiveness to Patients. New York: Oxford University Press.

Rogers, CR. (1957) The necessary and sufficient conditions of therapeutic personality change. Journal of Consulting Psychology, 21(2) 95-103. 
Rogers, CR. (1980) A Way of Being. Boston: Houghton and Mifflin.

Rogers, CR. (1986). A client-centered/person-centered approach to therapy. In I. L.

Kutash \& A. Wolf (Eds.), Psychotherapist's Casebook (pp. 197-208). San Francisco, CA: Jossey-Bass.

Spinelli, E. (1997) Tales of Un-Knowing: Therapeutic Encounters from an Existential Perspective. London: Duckworth.

Stern, DN. (2004) The Present Moment in Psychotherapy and Everyday Life. New York: W. W. Norton.

Stern, DN, Sander, LW, Nahum, JP, Harrison, AM, Lyons-Ruth, K, Morgan, AC, et al. (1998) Non-interpretive mechanisms in psychoanalytic therapy - The 'something more' than interpretation. International Journal of Psycho-Analysis, 79 903-921.

Tillich, P. (2000) The Courage to Be (2nd ed.). New Haven: Yale University Press.

Tryon, GS, \& Winograd, G. (2002). Goal consensus and collaboration. In J. C. Norcross (Ed.), Psychotherapy Relationships that Work: Therapist Contributions and Responsiveness to Patients (pp. 109-125). Oxford: Oxford University Press. 
Table one: Summary of major categories and sub-categories and frequency of responses

\section{CATEGORY}

Self-experiences

High level of empathy

Greater perceptual clarity

High level of congruence Impacted upon

High level of acceptance

Sense of immersion Free from distractions Immersed in the moment Like altered state of consciousness

Sense of aliveness

Feeling of satisfaction

Experiences/perceptions of the client

Transparent and real

Coming from 'core' of being

Coming from place of vulnerability

\author{
FREQUENCY \\ OF \\ RESPONSES
}

\section{Experiencing of the relationship}

Closeness/intimacy

6

Mutuality

Co-openness

Without masks

Co-acceptance

Client acknowledges therapist's acknowledgement 